
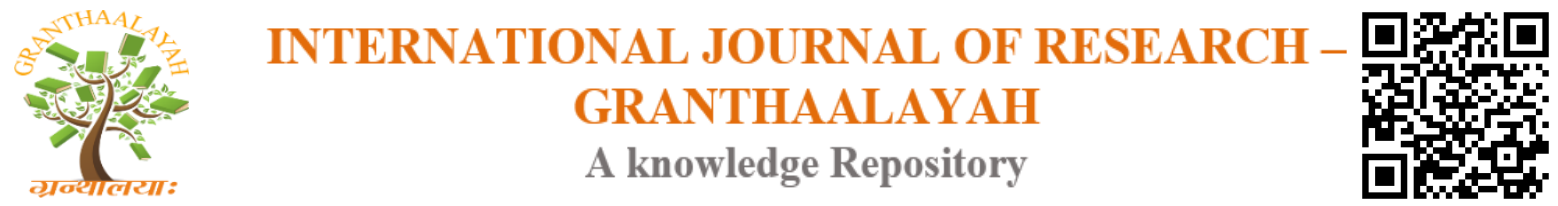

Science

\title{
INFLUENCE OF LIVELIHOODS ON HOUSEHOLD FOOD SECURITY IN PASTORAL AREAS OF NAROK COUNTY, KENYA
}

\author{
Timothy Kileteny ${ }^{1}$, Professor Jacob. W. Wakhungu ${ }^{2}$ \\ ${ }^{1}$ Masinde Muliro University of Science and Technology, School of Disaster Management and \\ Sustainable Development, Kenya \\ ${ }^{2}$ Masinde Muliro University of Science and Technology, Department of Agricultural Land Use \\ Management and Veterinary Technology, Kenya
}

\begin{abstract}
Food security and household livelihoods are tied together in an intricate relationship through the former's dimensions (availability, accessibility, utilisation, stability) and the latter's elements (Human, Social and Economic Capital). The problem identified by the study was a lack of information regarding the exact way in which the livelihoods of pastoralists in Narok County influence their food security. The study employed descriptive and correlation research designs. Data was primarily collected using questionnaires administered to a sample population of 385 , FGD, observation and KII. The objectives established that household food accessibility was largely influenced by economic capital (or the lack thereof); there was a general lack of money to buy food and or produce own food, against a backdrop of, slow onset drought disaster(four year long drought periods in the last 20years) unfavorable livestock prices, and physical access in pastoralist undeveloped land was hampered by poor road communication links. The low education levels (63.8\% were found to have never attained any formal education) implied limited economic opportunities for the household. Thirdly it was found that household food utilisation,(operationalised in the study as being access to potable water, latrine use uptake and household food storage practices) was influenced largely by social capital; based on the food module and other indicators of food utilisation as defined by the study, it was seen that the mean percentage status of food utilisation in Narok County stood at $49 \%$. The study concluded that livelihoods have a strong influence on food security, primarily through the social capital (traditional practices, extended family networks and support from formal institutions). The study findings will help enhance policy implementation, in areas of vulnerability to food insecurity for pastoralist households.
\end{abstract}

Keywords: Pastoralists; Food Security; Household Livelihoods.

Cite This Article: Timothy Kileteny, and Professor Jacob. W. Wakhungu. (2019). "INFLUENCE OF LIVELIHOODS ON HOUSEHOLD FOOD SECURITY IN PASTORAL AREAS OF NAROK COUNTY, KENYA." International Journal of Research - Granthaalayah, 7(9), 351-381. https://doi.org/10.29121/granthaalayah.v7.i9.2019.618. 


\section{Introduction}

Food security remains a pressing issue for communities around the world. The persistence of hunger and malnutrition continues to be a perennial problem, especially in the sub-Saharan region of Africa and the Caribbean where the prevalence of malnutrition stood at $3.1 \%$ and $33.9 \%$ respectively (FAO 2016). The same is true in South East Asia where the level had reached 11.5\% in the same period, while Latin America was at 5.6\% during the same period.

Since malnutrition and lack of food poses a grave danger to life and causes tremendous suffering to humans, it is imperative that each country explores means and ways of curbing food insecurity. Apart from human suffering, lack of food and malnutrition cost developing countries billions of dollars in lost productivity and national income. The number of undernourished people in the world is estimated to have reached 1,023 million in 2009. The proportion remains highest in sub Saharan Africa at $30 \%$ in 2010 (FAO, 2010).

But food security is a complex issue. A country or region is food secure when all people, at all times, have both physical and economic access to sufficient food to meet their dietary needs for a healthy and productive life. Food security depends principally on three variables: availability of food, access to food and utilisation. In turn, each of these variables is influenced by several factors, all closely linked to livelihoods.

Poverty, the national and international economic environment, population growth, infrastructure, climate change, level of investment and donor commitment, access to appropriate training and job skills, asset base, conflict and access to pasture and quality of diet, health, and sanitation also influence food (Kratli, 2001). These factors are contained in livelihoods elements. A livelihood, simply defined, is a means of making a living (Ellis et al., (2003). It encompasses people's capabilities, assets, income and activities required to secure the necessities of life.

Livelihoods are conceptually viewed as comprising various types of capital that can benefit an individual; specifically, human, social, economic and natural resources possessed by and at the disposal of a person (Chambers and Conway, 1992).

Human capital includes the demographic characteristics, skills, knowledge and ability to work of a person to be productive.; social capital comprises the formal and informal institutions, associations, extended family and local mutual support mechanisms or networks that cushion the individual's household against adversity; financial capital is the cash income, credit, and any other source of financial benefit; and physical capital refers to shelter, infrastructure and productive assets possessed by the individual Chambers and Conway, 1992).

It follows from this understanding that the households' food security, that is, the availability, accessibility and utilisation of food by a household depends on the strength of the livelihood elements. A livelihood is sustainable when it enables people to cope with and recover from shocks and stresses (such as natural disasters and economic or social upheavals) and enhance their wellbeing and that of future generations without undermining the natural environment or resource base. Livelihoods are universal. Poor and rich people both pursue livelihoods to make a living. However, the adverse impacts of weather related events and climatic changes increasingly threaten and erode 
basic needs, capabilities, and rights, particularly of poor and disenfranchised people, in turn reshaping their livelihoods (UNDP, 2007; Leary et al., 2008; Adger, 2010; Quinn et.al. 2011).

Some livelihoods are directly climate-sensitive, such as rain-fed smallholder agriculture, seasonal employment in agriculture (e.g. tea, coffee, and sugar), fishing, pastoralism, and tourism. Climate change also affects households dependent on informal livelihoods or wage labor in poor urban settlements, directly through unsafe settlement structures or indirectly through rises in food prices or migration.

Nomadism is a pastoralist strategy characterized by the movement of people and their livestock from place to place in search of pasture and water resources. Nomadic pastoralists therefore have no permanent abode. According to Omiti, (2002) Pastoralism is a nomadic livelihood, it refers to a range of livelihoods including pure nomadism and mixed agro-pastoral practices. Seasonal livestock migration follows relatively well-defined traditional stock routes that avoid disease vectors such as tsetse flies and ticks or social conflicts with other communities (Omitiet al, 2002). Due to reliance on natural resources, pastoral communities are particularly vulnerable to natural and human-caused disasters. Even under normal circumstances, pastoral communities often face extreme challenges in meeting basic needs due to significant reductions in land and water availability as a result of desertification, bush encroachment, soil erosion, population growth, and political and economic marginalization (Omitiet al, 2002).

According to Richard et al, (2006) Pastoralists constitute the majority of drylands inhabitants and, despite many efforts to change it, pastoralism still persists. Indeed, in Europe and Asia, policy makers are encouraging investment in pastoralism in the understanding that it is essential for sustainable environmental management in the rangelands.

Richard further opines that This flies position in the face of 'conventional wisdom', yet a closer look at desertification indicates that it often occurs where policies have, deliberately or inadvertently, undermined the pastoralist system, for example where settlement and irrigation schemes place an unwarranted pressure on the environment (Richard et al, 2006).

Where pastoralism has been enabled and supported by appropriate policies, ecosystem integrity and biodiversity have in fact been enhanced. The policy of sedenterisation in the drylands has been shown time and again to result in increased environmental degradation, reduced economic potential and eroded social and cultural systems. Rainfall in the drylands is low and unpredictable, both in terms of when it comes and where it lands (KFSSG, 2001).

'Natural hazards can affect anyone, anywhere. People are threatened by hazards because of their social, economic and environmental vulnerability, which must be taken into account if sustainable development is not to be achieved. Disaster risk reduction therefore concerns everyone, from villagers to heads of states, from bankers and lawyers to farmers and foresters, from meteorologists to media chiefs'.

The drought season triggers a sudden glut of livestock on the market, coupled with leaner malnourished livestock, means that prices fall and people have less money to buy food for the droughts (FAO, 2004). Several studies including the FAO findings have been carried out, and thus 
far few substantial solutions to food security amongst pastoral communities has been achieved and therefore forms the basis of this study.

\section{Livelihoods and Pastoralist Households}

A livelihood refers to the human, social, economic and natural resources possessed by and at the disposal of a person (Chambers and Conway, 1992). A livelihood comprises the capabilities, assets and activities required for a means of living. A livelihood is sustainable when it can cope with and recover from stresses and shocks and maintain or enhance its capabilities and assets both now and in the future, while not undermining the natural resource base (DFID, 2000).

Livelihoods are a dynamic process in which people combine activities to meet their various needs at different times. According to DFID (2000), livelihood strategies are directly dependent on asset status and policies, institutions and processes. Hence that poor people compete and that the livelihood strategy of one household might have an impact that is positive or negative on the livelihood strategy of another household.

Pastoralist household livelihoods in Kenya's are closely linked to overall development of the country and continues largely to be shaped in many ways by the country's colonial heritage of the kenya. The kenya territory's attraction to the British lay in the geo-political desire to control the source of the River Nile. The construction of the Kenya-Uganda railway line was based on the economic viability was based on the emerging settler agriculture economy. Hence, colonial government investments in social and physical infrastructure were based entirely to the parts of the country adjacent to the railway line as built and occupied by the European settlers, the agriculturally viable lands were called the 'White Highlands' and constituted the main focus of development of educational, social and economic structures (Tarus, 2005).

According to Tarus (2005), the rest of Kenya outside the Highlands that forms $75 \%$ of the land in kenya formed what came to be known as the Arid and semi-Arid Lands (ASAL) regions. Tarus asserts that these ASAL areas were denied investment intentionally so as to create 'native reserves' which interacted with the more developed parts of the country only through the sale of African labour induced through enforced taxation (Tarus, 2005).

The advent of labour for wages and subsequent taxation regimes largely according to Tarus ,(2005) excluded Kenyans occupying ASAL, partly because throughout colonisation and subsequent to colonial governments, the basic formal education structures were not developed in ASAL areas as commensurate as 'white highland' agro based zones, due to the nomadic nature of movement and settlement, the pastoralist way of life did not pre-dispose ASAL area inhabitants for the unskilled manual work that agro-based Kenyans did on settler farms and in corporations, such as railways and harbours as these pastoralists could not be at any specific area or at any specific time due to the nomadic movement.

The study by Tarus ,(2005) notes That, while colonialism rule penetrated and transformed the economic values of many (agro-based land occupying) Kenyans to embrace education and attendant employment ready skills, the colonial rulers unequal attention to ASAL area inhabitants meant that as Kenya gained independence a marginalisation entity that distinguished the ASAL regions from the former 'White Highlands' and the rest of the non-ASAL parts of the country was 
already a policy of government. According to Karingai the independent kenya assumed a tiered development has been perpetuated in the 50 years of independence through extensive public spending inequalities, which have had a long lasting effect on the opening up of economic development opportunities for ASAL marginalised areas (Bigsten, 1984; Kiringai, 2006).

According to Fitzgibbon, (2012) The national human poverty index fell by seven points to 29.1 between 2005 and 2009, it rose five points to 51.3 for arid counties The ASAL regions account for $80 \%$ of the Kenyan land area, but only $25 \%$ of the country's population, its pastoralist people keeping cattle, sheep, goats, camels and donkeys (Centre for Governance and Development, n.d). ASAL areas accounts for $50 \%$ of Kenya's total livestock population, amounting to some $1.6 \mathrm{mn}$ tropical animal units which provide $90 \%$ of the regions' employment and $50 \%$ of their household incomes. At the national level, livestock's importance is reflected in its $10 \%$ share of GDP, $42 \%$ share of agriculture GDP, and 50\% share of the national agriculture labour force. The ASAL regions have been characterized by a four-year cycle of major droughts, whose intensification is suggested by the three instances in the last 10 years, i.e., 2006, 2009 and 2011 (Fitzgibbon, 2012). The regions are also characterized by widespread livestock theft, animal diseases, conflicts over the animals and their diminishing pastures and water, and a poor exposure to markets for their livestock.

Pastoralists inhabit zones where the potential for crop cultivation is limited due to low and highly variable rainfall conditions, steep terrain or extreme temperatures. Within this unpredictable, vulnerable and dynamic environment, they have developed various mechanisms of adaptation to maintain an ecological balance between themselves and the natural environment (Rota, 2016).

According to McPeak ,(2006), the nature of pastoralist livelihoods is such that some households that cannot or do not adopt agricultural or agro-pastoral practices are more susceptible to food insecurity than others that have already adopted alternative livelihoods, by the nature of the ASAL they inhabit, pastoralists tend to be the most vulnerable to extreme weather conditions.

The main source of pastoralist income and nutrition is their livestock, which depend on grasslands, pasture and water puns and, thus, weather conditions. Nonetheless, the ASAL areas that form the abode of most of these pastoralists rarely allow for some of these changes in land use e.g. farming. Financial services are also not readily available to pastoral households. There is a need to take these changes into account in the design of drought management systems (McPeak, 2006).

The FAO, (2004) study observes that during the wet seasons, pasture and water sources are abundant, the local markets are thriving and livestock prices can be favourable. however, once the short seasonal rains subside, an extended drought period hits the pastoralist areas and pasture and water sources become depleted, people sell their livestock to raise money to buy food. The UNISDR (2014) study observed that

\section{Livelihoods Assets}

The Livelihoods assets is concerned with human survival, it seeks to gain an accurate and realistic understanding of people's strengths that being assets or capital. Chambers, (1992) asserts that it is necessary to analyse a peoples' endeavour to convert capital nd asset strengths into positive 
livelihood outcomes. The livelihoods approach is founded on a belief that people need a range of assets to achieve positive livelihood outcomes (Chambers, 1992).

According to Chambers, (1992) it is within sustainable livelihoods framework SLF that distinct assets are identified as five types of assets or capitals upon which livelihoods are built, namely human capital, social capital, natural capital, physical capital and financial capital.

The SLF seeks to take a more comprehensive and integrated approach to poverty than traditional interpretations, and largely considered poverty in relation to a narrow set of indicators such as income and productivity according to Lucius, (1954).

Sustainable Livelihoods Framework was developed in order to organize and improve organizations' efforts to eliminate poverty. The SLF enables a form of analysis which identifies people's strengths rather than their needs. People are seen (Eva \& Rachel, 2008) as actors who have assets, capabilities, and use them to pursue their own livelihood goals, rather than being perceived as victims or simply beneficiaries.

\section{Human Capital}

Human capital refers to the human capabilities possessed by an individual. This includes the skills, knowledge, ability to work, and the physical and mental health that enables a person to be productive (Chambers and Conway, 1992). Pastoralists possess rich indigenous knowledge but have very poor access to human health and formal education.

The DFID (2000) study is in agreement with the SLF framework that was advanced by Chambers and Conway (1992), who state that human capital encompasses the health of an individual, household and community; social capital comprises social resources, which are considered to be associations between individuals, increasing productivity by reducing the cost of doing business and facilitating coordination and cooperation of the society.

A study by International Institute for Environment and Development iied, (2009) asserts that Learners from nomadic pastoralist communities face peculiar difficulties in accessing and continuing with education programmes whose designs suit sedentary communities. Standard curriculum delivery services which are designed for the majority are tailored for 'static' situations where children learn in classrooms in permanent locations. The importance of mobility and young people's labour to pastoral production, the low population density of many arid areas, and the challenge of ensuring that a national education system is relevant to pastoralists' needs and values are just some of the reasons why educational participation and achievement is often much lower in pastoral areas of many countries in Africa than the national averages. The situation is worse for girls.

According to GEF, (2007) health and education indicators are often far worse in pastoralist areas relative to national-level figures, livelihoods are prone to shocks, trends and seasonality of whether patterns for agriculture, pastoral and agro-pastoral based communities. Kenya's ASAL counties have the country's poorest human welfare indicators. For example, the former North Eastern Province's (NEP) Human Development Index (HDI) stands at 0.417 compared to the national average of 0.562 and Central Province's 0.624 NEP includes Garissa, Mandera and Wajir, while 
Central Province includes Kiambu, Muranga, Nyeri and Kirinyaga. (UNDP, 2010). These HDI disparities reflect the development deficit faced by ASAL regions Narok is classified as a semiArid area although it has two main ecological zones: the highlands in which rain fed agriculture is practiced and the fragile lowlands which are mostly used for pastoralism.

\section{Social Capital in Livelihoods}

Social capital has variously been described by scholars as 'the networks and relationships that people develop and use to build trust and enable them to work together effectively and efficiently; relationships of reciprocity and exchange; working in cooperation; providing safety nets and support' (Nyanjom, 2014).

According to Chambers ad Conway (1992), social capital refers to the formal and informal institutions, associations, extended family and local mutual support mechanisms or networks that cushion the household against the adverse effects of the disaster. Barbier and Hochard (2014), aver that social capital encompasses an aspect of social relations offering a dynamic space where people interact, define and pursue, individually and collectively, principles and objectives, means and ends for well-being.

The relationships between human well-being and land are still not getting appropriate policy attention. this was noted by Nkonya, (2016) who also observed that the research and action community concerned with the consequences of degradation of land and soils, and the need for sustainable land management, has grown rapidly has picked up momentum Over the past few years, (Nkonya, 2016).

\section{Economic Capital}

Economic capital refers to, physical and natural capital possessed by an individual. Natural capital refers to the natural resources available, such as farms, grazing land, forests, wildlife and water from which people derive their livelihood; Physical capital: Refers to shelter, infrastructure and productive assets possessed by the individual.

According to Barbier and Hochard (2014), physical capital includes equipment such as a tractor on a farm, a sewing machine for a tailor and buildings and computers for the community. Financial capital includes financial assistance for entrepreneurs and small businesses that lack access to banking and comparable services. The study is in agreement with the SLA model, which indicates that the capabilities and assets (including both material and social resources) support a means of living.

Financial capital comprises tangible inflows of cash from income generation activities, gifts from well-wishers, as well as stocks of consumer goods such as livestock and savings from income earned by and held by a family. Pastoralists communities have relatively high financial assets in the form of livestock and in some areas, also cash remittances from educated and entrepreneurial kin in diasporas away from ASAL areas Natural capital includes land, water, air, living organisms and all ecosystems on the earth that are necessary for human survival and well-being. In general, natural capital refers to natural resources that are available in the community (GEL,2007) 
The study by GEL (2007) notes that residents of ASAL areas however being nomadic/pastoralist communities also face high vulnerability to, capital losses from normal economic activity in livestock trading and weather vagaries from sudden onset of drought events leading to food insecurity (GEL,2007).

\section{Pastoralist Livelihoods}

Small-scale livestock production is a major contributor to the economies of sub-Saharan countries, especially for the rural populations. It also plays an essential role in food production, and the protein provided by livestock products is an important component of this (Rass , 2006)..

There are 120 million pastoralists worldwide, 50 million of these in sub-Saharan Africa where they constitute $12 \%$ of the rural population (Rass , 2006). The Fulani are the primary pastoral group in Nigeria with a population of approximately 15.3 million. The Fulani first settled on the Jos Plateau around 1910, attracted by the low levels of disease and abundant grasslands, and are present in large numbers till today (Blench ,2004).

Pastoralists reside in over 21 countries across the African continent. Pastoralism is a major economic production strategy in which people raise herds of animals, mostly in arid and semi-arid lands (ASALs). ASALs cover about $80 \%$ of Kenya's landmass and support about a third of the country's human population and $70 \%$ of the national livestock herd. An estimated 13 million cattle, 25 million goats, 14.9 million sheep, 1.7 million donkeys and 2.9 million camels are found in Kenya's ASALs (KNBS, 2010).

According to Opiyo et al. (2014), ASAL areas are prone to Drought periods of months and years that gets less than the annual average rainfall and results in a severe scarcity of water affecting moisture for biomass growth of grass and direct consumption. Drought according to accounts for water scarcity and contributes to a higher vulnerability among the mobile pastoral communities who are the endemic population to drought effects, drought is classified as a slow onset disaster due to it accumulative impact of losses of livestock herds over a period to their livelihoods. hence, it causes severe economic, social and environmental losses in both developing and developed countrys (Opiyo et al.2014).

The highest livestock populations are held by the Turkana and Pokot pastoralists of north- western Kenya (GoK,2010). Pastoralism contributes approximately 12\% to the country's Gross Domestic Product GDP (FAO 2005), with the livestock sector providing an estimated $90 \%$ of all employment opportunities and more than $95 \%$ of household incomes in ASALs (Kaimbaet al., 2011).

Pastoralism practiced by the majority of Maasai, Turkana and Pokot ethnic groups is mainly nomadic transhumance, which is characterized by risk-spreading and flexible mechanisms, such as mobility, communal land ownership, large and diverse herd sizes, and herd separation and splitting (Opiyo et al.2011). The livestock types kept by these communities to manage and spread risk include cattle (zebu), camels, goats, sheep and donkeys.

Livestock possession plays multiple social, economic and religious roles in pastoral livelihoods, such as providing a regular source of food in the form of milk, meat and blood for household 
members, cash income to pay for cereals, education, health care and other services (Opiyo et al.2011).

In pastoral communities, livestock is also essential for payment of dowry, compensation of injured parties during raids, symbol of prosperity and prestige, store of wealth and security against drought, disease and other calamities. Livestock is therefore a fundamental form of pastoral capital, besides functioning as a means of production, storage, transport and transfer of food and wealth (Behnke,2008).

\section{Food Security}

According to the United States Development Agency (USAID), food insecurity is a situation whereby a household has limited or uncertain availability of nutritionally, adequate and safe foods or limited or uncertain ability to acquire acceptable foods in socially acceptable ways (Valentine (1997). Food security as a concept has been changing over time, depending on what the scholars and other stakeholders perceived to be at stake. In the 1970s when food security as a concept took the limelight, the emphasis was on food supply.

After the 1974 World Food conference, the definition which encompassed vulnerability as a factor broadened. From this conference food security has been defined as "availability at all times of adequate world food supplies of basic foodstuffs to sustain a steady expansion of food consumption and to offset fluctuations in food production and prices" (FAO 1974)

In the late 80 s a distinction was being made between chronic and transitory food insecurity, the new definition included the idea of enough food for an active and healthy life. By the mid 90s the definition widened from the individual to a global level, and access encompassed food composition and nutritional value (FAO, 1996).

The definition is daily evolving as various variables of food security or insecurity as may be takes centre stage. This study adopts the definition of food security as provided by the World Food summit of 1996 that defines food security is "when all people, at all times have physical and economic access to sufficient, safe and nutritious food to meet their dietary needs and food preferences for an active and healthy life" (FAO, 1996).

\section{Food Availability}

The World Food Programme defines availability as "The amount of food that is present in a country or area through all forms of domestic production, imports, food stocks and food aid". (WFP, 2009). Rielyet al 1995, confirms that the term tends to be applied to food available at a regional or national level rather than at the household level, which can lead to some confusion as the word "availability" sometimes is used at the micro-level.

A study by Erle, (2016) observes that People have been modifying land to obtain livelihoods and other essentials such as food for thousands of years. Erle also avers that the current rates of use, extents and intensities of land cover change are far greater than ever in history, and have driven unprecedented changes in ecosystems and environmental processes at local, regional and global scales. Ele, (2016) asserts that these changes encompass the greatest environmental concerns of 
human populations today, including climate change, biodiversity loss and pollution of water, soils and air.

In a study of 2013 Adunga, (2013), observed that the increase in global agricultural production thus far has outstripped population growth and that according to different estimates, current agricultural production could feed 10 to 14 billion people if it was used exclusively and as efficiently as possible as food.

The Kyoto, Hyogo and Sendai climate change protocol, (UNISDR 2015) outline that land tenure constraints and inadequate services are amongst contributing factors of land degradation also in ASAL Semi ASAL areas which are exacerbated by socio-political and economic barriers, and political marginalization of, pastoral and agro pastoral communities.

According to Constance, Sally, and Andreas (2010), Pastoralists by the nomadic nature of a nonsedentary life are unable to advocate for adequate services due to the constant movement and migration of homes, which exposes pastoralists to political marginalization hence nomadic pastoral and agro pastoral communities' livelihoods are closely linked to food security.

Further according to UNISDR (2015) The Hyogo Framework for Action HFA (that was a planning tool of the UN from 2005 to 2015) matters because food security disasters affect accessibility and availability of food, similarly development and poverty are intimately linked.

The definition of disasters that the framework addresses is wide-ranging, and includes worsening droughts, heat waves, wildfires, floods and severe storms which impact on land erosion and degradation and which scientists have linked to anthropogenic climate change - as well as earthquakes, tsunamis, volcanoes, landslides and disease epidemics the HFA endeavours building the resilience of nations and communities to disasters (UNISDR ,2015)

Destruction of assets and livelihoods in disasters set back hard-won development gains and worsen poverty, often for extended periods of years. Progress in ending extreme poverty may be reversed in the face of a disaster event and poverty re-entrenched (UNISDR 2015).

The FAO, 2016) study observes that land use planning is even more crucial today, with growing pressures from climate change, urbanization and biofuels. Much high potential land is being lost to settlements; land which previously grew food crops is being planted with feedstock for biofuels rather than food; climate change is limiting arable cropping in dry lands, reducing productivity of rangelands and increasing sea levels, creating problems in coastal areas the pastoralist community is particularly exposed due to the non-agricultural practices or agro-pastoral livelihoods. (FAO, 2016).

Since agriculture holds so many of the answers to challenges posed by changing weather patterns, it makes sense that this sector takes centre-stage in climate change negotiations, further it outlines the vulnerability of pastoralist communities to food insecurity (CGIAR, 2016). 


\section{Food Accessibility}

The World Food Summit defines access as having "physical, economic and social access". Access is still not commonly accepted as an essential part of food security despite Amartya Sen's introduction of the concept in the early 1980s.

Many people only consider access within an economic or financial context, particularly since the 2005 Niger food crisis and the start of food price volatility in 2008. The World Food Programme defines food access as "A household's ability to acquire adequate amount of food regularly through a combination of purchases, barter, borrowings, food assistance or gifts”. (WFP, 2009).

Food access consists of three elements, which are physical, economic/financial and socio-cultural. The physical dimension can be illustrated by a situation where food is being produced in one part of a country but an inefficient or non-existent transport infrastructure means that food cannot be delivered to another part suffering from a lack of food.

From the economic viewpoint, food security exists when people can afford to buy sufficient food. The idea that food insecurity arises when food is available but people are unable to afford it is still quite a recent development in the history of food security. A further economic consideration is the importance of market systems to ensure access to food as OXFAM points out: "Even in rural areas most people, and especially the poor, rely on market systems to provide food and essential goods and services but also for selling their produce". (OXFAM, 2007).

The third element is the socio-cultural dimension which arises when food may be physically available and the potential consumer has the money to buy the food but is prevented from doing so for being a member of a particular social group or even gender. Social conflict and civil strife can seriously disrupt food production and lead to the loss of livestock for example with dire consequences for a household's future food security (Riely et al. 1999).

\section{Food Utilisation}

The World Food Summit's definition of utilization (the third element of food security) is "safe and nutritious food which meets their dietary needs". The availability of and access to food on their own are not enough, people have to be assured of "safe and nutritious food". The food consumed has to provide sufficient energy to enable the consumer to carry out routine physical activities. Utilization also covers factors such as safe drinking water and adequate sanitary facilities to avoid the spread of disease as well as awareness of food preparation and storage procedures. Utilization therefore covers a range of aspects that hinge on the consumer's understanding of what foods to select and how to prepare and store them. It is often a mistake to assume that the members of socalled traditional societies know how best to use food resources and it is also a fact that dietary habits (breast-feeding, weaning foods) change very quickly, even for traditional societies.(Napoli et al., 2011).

\section{Social Capital and Food Security Culture, tradition and Religious Affiliation}

According to Matsumoto et al (2012)human culture is defined as "a unique meaning and information system, shared by a group and transmitted across generations, that allows the group to meet basic needs of survival, pursue happiness and well-being, and derive meaning from life.". 
By inference the survival includes food for survival. This meaning and information system involves a body of shared knowledge and learned experience that includes beliefs, practices, norms and values, and is shaped by the social, economic and ecological environment of a group (Matsumoto and Juang, 2012).

In a socio cultural network the extent to how food is made available for use at household level. Alonso (2015) posits depends on that culture, religion and traditional knowledge determine intrahousehold food distribution patterns, which therefore affects availability. Cultural practices are propagated from one generation to another, and therefore not easy to break.

Many religions in almost all societies assign symbolic value to food, and require their adherents to follow strict rules and regulations that require them to eat certain foods at certain times, abstain from some foods, and even fast periodically (Sabaté 2004). According to Kuhnlein and Receveur (1996), the availability of nutrient-rich foods may be affected by the traditional practices in the community. People will either stick to consuming traditional foods, or move away from them to modern imported market foods.

According to Colding and Folke (2001) there are food taboos that serve to protect natural resources from overexploitation may contribute to ensuring the availability of food. On the other hand, it is argued that safe and nutritious wild edible plants and traditionally consumed local food plants may contribute substantially to the local availability of nutrient-rich foods (Uusikuet al. 2010).

The foregoing literature points to how the food accessibility domain of food security is influenced by cultural factors. It informs the study by providing valuable insights into key variables, but also points to an information gap that the current study seeks to fill regarding how social capital influences food accessibility in Narok county.

In a paper that reviews case study literature on the role of culture, religion and traditional knowledge as drivers of food and nutrition security in developing countries, Alonso (2015) asserts that culture, religion and traditional knowledge shape local diets, and are responsible for food processing and preparation techniques, as well as health and sanitation practices. In this way they affect the food utilisation dimension of food security.

Food utilization is also affected by culture, religion and traditional knowledge. Henrich and Henrich (2010) argue that food taboos potentially protect communities from consuming toxic products. On their part, Liu et al. (2011) assert that culturally evolved knowledge embedded in traditional food systems may dictate how to process and prepare foods so as to increase the nutritional value and decrease the anti-nutritional or toxic value. (Liu,et al., 2011).

According to Tapsell et al. (2006), traditional food systems may involve knowledge regarding which combinations of foods increase the nutritional content and bioavailability of nutrients.

Illness and health problems can limit the absorption of micronutrients, further aggravating the morbidity. Adams et al. (2005) state that traditional cultural or religious beliefs and practices related to pregnancy, childbirth and the postpartum period may significantly affect health seeking behaviour and access to public health services (Adams et al. 2005). In addition to this, traditional 
medicine continues to be prevalent and may present the only available, affordable and culturally acceptable form of health care for poor and food and nutrition insecure groups (Alonso,2015).

Recent research has shown that the traditional knowledge embedded in traditional medicine may prove highly useful in the development of new drugs and alternative affordable therapies (Fabricant and Farnsworth 2001). However, Maslove notes that the use of traditional medicine also presents risks, such as harmful therapies and delay of effective treatment (Masloveet al, 2009).

\section{Formal and Informal Institutions (Government and Non-governmental Organisations)}

A study by Premarathne (undated) argues that, contrary to the conventional belief that agricultural development in developing countries primarily depends on the provision of formal institutions, many countries have recognized from their past experiences that formal institutions alone will not help to achieve agricultural development without positive support from their informal institutions. The scholar goes on to assert that the basic argument for the role of informal institutions in economic activity is that it reduces transaction costs. In most developing countries, particularly in their rural agricultural sector where the formal institutional architecture is either absent or in a poor state, the informal institutions gain prominence by playing a more active role in reducing any kind of transaction costs that engage in all the stages of their agricultural value chain Premarathne (undated).

\section{Economic Capital and Food Security Education Level}

According to Alonso (2015) economic growth is a strong predictor of the level of food and nutrition security in a country, and is strongly linked to the level of education that often determines the bargaining power in wage negotiations and income earnings that contribute to economic growth in addition to other factors such as the growth in food production, female secondary education and access to health services.

The oxford dictionary defines 'education'، as an act or process of acquiring knowledge' whereas schooling schooling is more narrowly defined as 'the process of teaching or being taught in a school scholars a argued that the two words are often used in similarity and synonymously whereas as asserted by Janssen, (2005) they are different and applicable only in communities with well developed social infrastructure and amenities Jansen argues that Narrowing the broader notion of 'education' to mean 'schooling' has important implications and should not go uncontested.

According to (see Jansen, 2005) "Educational target setting is problematic on many fronts but may at least have had the positive outcome of highlighting the unmet educational needs of groups who cannot easily be enrolled in existing models of primary schooling. Problems with reaching such groups with schooling, and the resulting challenge to the agreed targets, underlines the need to think about the suitability of formal schooling for meeting the educational needs of today's diverse and complex societies".

A study by Tomasevski, (2003) highlights the need of getting all children to school I as important for them to get education Tomasevski assertion that not necessarily the only focus (or the right one) is pertinent to the Training and education sector in ASAL areas and Narok county pastoralist 
areas where reaching /locating the populations that require education for ensuring their right to education as outlined by the MDG (UNSIDR,2015).

According to (UNDP, 2010). The Human welfare index is very high in ASAL areas and is contributed to marginalisation policy perpetrated since colonial rule, that has seen low development of school facilities in Narok county and has had a equally low attendance level of school age boys and especially girls, this situation has in turn had a negative effect on livelihood diversification as the training and skills needed to get employment and occupation in other income generation activities have been greatly affected by under-development and ASAL nature of the environment Nyanjom ,(2014).

According to Dolan, (2004) options for education for populations that occupy vast ASAL areas in Australia are made available through the use of virtual classrooms that utilise technology through computers modems and transmission equipment to link up the children and youth in far flung areas that have no formal schools. The semi -arid environmental situation obtaining in Narok Kenya is characterised by vast areas of free rangeland occupied by the Masaai, but underdevelopment of social infrastructure and schools limits the potential for remote schooling (Nyanjom .2014).

\section{Income sources and Level}

Generally, where there are diverse sources of income including, formal employment, informal employment, business farming and livestock keeping, and where the income is high, the household enjoys better food availability, accessibility and utilisation (FAO.2007).

Income sources in Narok Kenya are limited to livestock herding due to the ASAL nature of the environment, opportunities for formal and informal employment opportunities in Narok are few and far in between. employment offers a diversification option to earn better and more income to achieve food security, but this option is not easily available to the pastoralists of Narok (Nyanjom .2014).

According to UNDP, (2010) human welfare index is severely affected by the latent lack of infrastructure such as roads, markets schools Training colleges and universities, this in turn affects the potential to train entrepreneurs and set up trading centres for businesses a factor that is also contributed by the stagnant migratory culture that inhibits sendentisation.

According to Sitatiet al (2003) the ASAL areas of Narok are also dispersal and migratory paths for wildlife and an interaction with humans often leads to a human wildlife conflict, which is manifested in wildlife invading areas cultivated for food crops and lack of trading centres that are inhibited through concerns for safety from wildlife.

\section{Ownership of assets and access to Credit}

Ownership of assets is an indicator of economic strength. Usually in hard times a household will dispose of its assets to get money for its basic needs. In certain instances, assets can even be bartered directly in exchange for food.

According to UNDP, (2010) the development of infrastructure is a key factor of the human welfare index, which in turn contributes to accumulation of wealth and ownership of assets, asset 
ownership in Narok is confined to herds in livestock and due to the pastoralist and cultural nomadic migratory nature of life few other assets are accumulated or owned.

\section{Livelihoods and Household Food Security in Pastoral Areas}

Traditionally, pastoralists employed various coping mechanisms to sustain their pastoral economy. To minimize risk in a variable and unpredictable environment, they adopted four mechanisms stock mobility, herd maximization, herd diversification and herd dispersion, Galatyet al (1981).

Stock mobility ensured that animals accessed fresh pastures, sufficient minerals, and water supplies and avoided overgrazing, competition, diseases. It was also a technique of expansion. Herd maximization entailed keeping as many female animals as possible to ensure adequate production level of mainly milk and milk products necessary for the sustenance of the household. It was also a mechanism of building a large herd for survival, minimize risks and for recuperation after drought Galatyet al., (1981).

Under the same management, pastoralist combined different species - cattle, goats, sheep, and camels. The strategy reduced the risk of total loss as different species of animals are susceptible to different disease risks. In addition, it also ensured efficient use of available pastures as different species had different non-competing grazing habits. Similarly, the strategy increased productivity. Herd dispersion involved spreading one's animals to several localities to counter the risks of theft and disease, Galatyet al (1981).

However, the conditions that supported pastoralism and their traditional coping strategies have been affected by persistent drought, climate and socio-economic changes such as population pressure, the development of roads, human and animal care, government policies, urban expansion, expansion of cropping, political instability, land tenure disputes as well as settlement policies, advancement in technology and penetration of a market economy Mung'ong'o et.al (2003).

Thus, pastoral systems have increasingly become vulnerable, unsustainable and are declining in Sub-Sahara Africa (SSA), North Africa, India, Near East, South Central Asia, Europe, North and Central America Mung'ong'o, (2003).

The decline of pastoral systems has been accompanied by a diversification into non-pastoral activities Smith et al., (2001). In the Middle East, Syria, Jordan, Sudan, and Tanzania, wage labour and employment in urban areas, military service, and industrial areas and tourism is increasingly becoming a livelihood option mostly for pastoral youths. Similarly, in Syria, Mali, Sudan, Ethiopia, and Tanzania, pastoralists are diversifying into crop cultivation directly or indirectly and either for subsistence or commercial purposes.

Other activities pursued include, petty trading, beer brewing and prostitution, as well as running shops and sale of milk in Tanzania, Ethiopia and Somalia respectively Smith, et al., (2001).

In Mongolia, households of herding communities had turned to hunting of game as an alternative activity to generate income while in Ethiopia; herders diversified into additional animal species (UNDP, 1997). 
Kenya livelihoods and Household Food Security in Pastoral Areas

In Kenya, the on-set of disaster has been slow due to several drought (sometimes year long ) seasons , pastoral households in the northern, coastal and eastern regions have adopted short-term strategies such as reciprocal raiding of livestock, charcoal production, selling breeding stock, consuming wild fruits as well as hunting wild game and even tourism.

More specifically, the Maasai of Simanjiro district of Tanzania as well as Narok and Kajiado districts in Kenya are diversifying into livestock trade, wage labour; milk markets, shop-keeping, selling meat, small businesses, crop cultivation and quarrying Kristjanson, (2002). They are also diversifying their livestock production system to include cattle, sheep and goats and the proximity to game parks and reserves makes tourism a source of income. Wealthy Maasai are adopting commercial livestock production Zaal, (1999).

The three Maasai sections of Isiria, Ilmoitanik and Ilwuasingishu reside in Transmara. Historically, IsiriaMaasai were already in Transmara by 1910 and pastoralism has been their livelihood strategy. Traditionally, this activity satisfied their needs as grazing land, natural water sources, forests and salt licks were available to all stockowners in the community. Similarly, their flexible social structure and settlement pattern as well as low populations of livestock and humans were suitable for this mode of production. The Purko, Ildamat and keekonyokie who reside in the Larger Narok practiced both pastoralism and mixed farming, depending on their settlement area.

\section{Kenya's Policies and Plans}

Kenya's first National Food Policy (Sessional Paper No. 4 of 1981), later consolidated into Sessional Paper No. 1 of 1986 on Economic Management for Renewed Growth, aimed to maintain broad self-sufficiency in major foodstuffs and ensure equitable distribution of food of nutritional value to all citizens (GoK, 1994).

This was to be achieved mainly through Government interventions, such as setting grain prices, state monopoly of input distribution, and across the board fertilizer subsidies. Following the 199194 drought, Kenya's second National Food Policy (Sessional Paper No. 2 of 1994) promoted a market-driven approach, but on a limited scope (GoK, 1994).

According to National Policy for the Sustainable Development of Northern Kenya and other Arid Lands, 2015, focuses on pastoralism is justified for two main reasons. First, pastoralists are among the groups most marginalized with limited access to socio-economic services and infrastructure. Successful achievement of national and international development targets will depend on the extent to which attention is given to the distinct challenges facing pastoral communities (GoK, 2015).

The second reason is that, until recently, most governments particularly in Africa viewed pastoral areas as net consumers of national wealth that offered poor prospects of return on investment. Pastoralism was therefore less valued than other forms of land use and less well-supported. Recent studies have shown that these views were misplaced. As a result, Governments in several countries, including Kenya, now recognize the strengths of pastoralism and have formed ministries or other authorities to enhance the contribution of pastoralism to food security, environmental stewardship, and economic growth. African Union recently adopted a policy framework for pastoralism in 
Africa where it seeks to secure, protect and improve lives, livelihoods and rights of pastoralist communities (GoK, 2015).

\section{Theories and Models that Informed the Study Livelihoods Model}

The livelihoods concept of model as propounded by Chamber and Conway (1992) identifies key strengths or capita that comprise an individual's livelihood. Namely, these are human capital, Social Capital; Natural Capital, Physical capital and Financial Capital and can be further classified as both material and social, a study by Young. $\mathrm{H}$ et al, (2002) avers that for survival and longerterm well-being a livelihood should be sustainable in being able to cope with stresses and shocks such as (drought, flood, war), maintain and enhance resilience through accumulation of material and social capabilities without undermining natural resource base and reduce vulnerabilities that are created by natural hazards and exposure to man-made risks.

This model was found useful for the current study in identifying key elements in an individual's that likely influence the household food security (FAO ,1996). The model was modified by the researcher to fit the needs of the study; human capital was confined to the age, gender and morbidity; social capital was defined by culture, tradition and religious affiliation, as well as formal and informal networks; economic capital was defined as education level, income level and sources, ownership of assets and access to credit(AWSC, 2015).

The livelihood model is applicable in for survival and well-being of a community the pastoralist way of life is however confronted by several challenges in form of semi-arid climate and climate change, manmade lack of adaptation development of social and communication infrastructure and nomadic cultural non-sedentary life.

\section{WFS Food Security Framework}

The 1996 World Food Summit declared and subsequently reconfirmed in 2002, food security consists of four essential parts, namely food availability, food access, food utilization and stability. Figure 2.1 shows how the categories in the framework relate (AWSC, 2015).

According to FAO, (2007) livelihoods and food security have to be looked at in firstly in the vulnerability context which refers to components 'that impact on people's livelihoods and can exert risks of food insecurity. Vulnerability is made up of the structural or underlying vulnerability of a population and the vulnerability to particular external shocks. which people have limited or no control: these components include population pressures on land, land degradation, climate change, price inflation and shocks that impact livelihoods like drought" it is noteworthy that the pastoralist community of Narok faces all these challenges that impact on the community's ability to secure food security,(FAO, 2007).

The pastoralist of Narok county are less prone to floods, but pest attack, market collapse and conflict/insecurity are risks and hazards that the community faces from time. Seasonal stresses such as disease burden, water shortages or food shortages in the hungry season are other components that FAO, (2007) points out impact on morbidity human capital and exposes the Narok pastoralist peoples to food insecure livelihoods. 
The FAO, (2007) Checklist on components that impact livelihoods includes Livelihood resources and assets, Policies, institutions and processes that have a political persuasion and slant, Livelihood strategies that include options such education and training for the employment wage market and diversification of livelihood occupations to agro-pastoralism and commodity exchange trading. The WFS Food Security Framework ideal in the context of pastoralist community in Narok explores the limitations imposed by cultural practices in livelihood and food diversification choices.

\section{Hunger Module}

The African Women's Studies Centre (AWSC), of the University of Nairobi undertook a countrywide Household Baseline Survey on Food Security in collaboration with the Kenya National Bureau of Statistics (KNBS), to establish the status of food security in the country. A household survey was used to interview respondents on their food security status using a hunger module to assess household experiences in the last 10 months before the study (AWSC, 2015)

The framework comprises a physical determinant (the first three elements) and a temporal determinant (the fourth). Food might be available but that does not determine access; similarly, access might be viable but does not guarantee utilization.

and all three can be disrupted by a lack of stability caused by climate change, conflict, unemployment, disease or other factors. Stability or the lack of it can affect any or all of the other three components of the food insecurity framework (AWSC, 2015)

The survey addressed the issues of availability, access, utilization, and sustainability of food.

Source: FAO (1996)

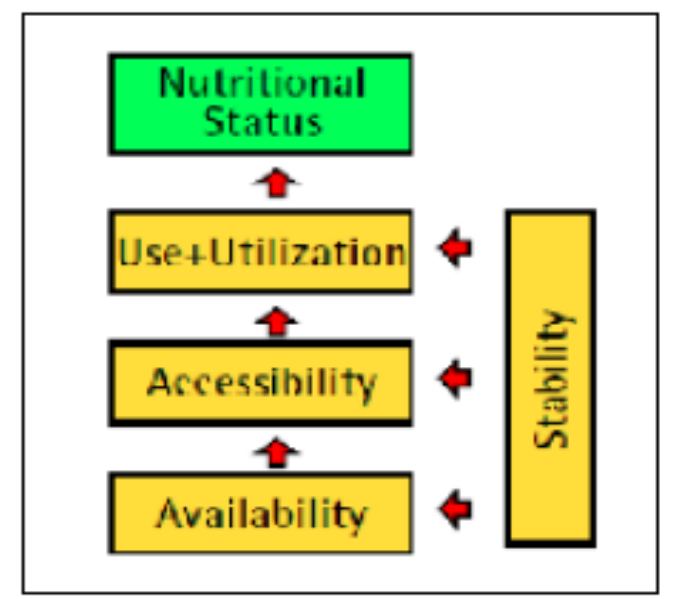

Figure 2.1: The Food Security Framework

The AWSC used the food security framework to focus on hunger as a major manifestation of food insecurity in the country. The study adopted eight questions to measure the four dimensions of food security as illustrated in Table 2.1. the current study adapted the same to establish the food security status for pastoralist households in Narok county. (AWSC, 2015). 
The study used the food security framework to explore the effect of livelihoods and food options available to pastoralist households in Narok county the nomadic culture poses special challenges in food choices and availability.

\section{The Conceptual Model for the Study}

The foregoing were the frameworks used to develop a conceptual model for the study. Mugenda and Mugenda (2003) say a conceptual framework is a graphical or diagrammatic representation of the relationship between variables in a study. It helps the researcher identify the proposed relationship between the variables easily and quickly.

The conceptual framework model examines the livelihood options available to the pastoralist community in nomadic culture context and diversities are deemed to be independent variables that determine asset accumulation and income generation potential (FAO,2007).

The food security framework model explores the elements of food security that are available to the pastoralist community of Narok county Kenya, the food security components are faced by special challenges posed by the nomadic culture and livelihood choices made by the pastoralist community of Narok and the potential livelihood diversities available in the semi-arid environment (AWSC, 2015).

The intervening variables are informed by the historical context of political decisions made on development of arid and semi-arid areas since the colonial government regimes policies that have spilled over from marginalisation of ASAL areas and optimum use of ASAL areas through habitation and environmental conservation (FAO,2007).

\section{The Conceptual Model for the Study}

The foregoing were the frameworks used to develop a conceptual model for the study. Mugenda and Mugenda (2003) say a conceptual framework is a graphical or diagrammatic representation of the relationship between variables in a study. It helps the researcher identify the proposed relationship between the variables easily and quickly.

\section{Objectives}

This article aims to present the coping strategies of the pastoral community's livelihoods assets contribution on household food security in Narok county kenya, using data from various stakeholders who were the conservation associations, CBOs, FBOs, Other Ngo Reps, Traditional leaders Nomadic pastoralist community Manyatta/Household, business community and other members of the public.

This publication presents the Food security and dimensions: (availability, accessibility, utilisation, stability) and the household livelihoods elements; (Human, Social and Economic Capital) brought about by the Pastoralist and Nomadic inhabitants of Narok county ASAL areas.

\section{Methods}

Data for this study were collected in 3 steps. The first step involved reviewing reports from government reports from NMDA, Central and county government agriculture and livestock administration, books, periodicals, journals, newspapers and magazines by conservationists and scholars on climate change resilience in Kenya and other countries.to assess the current trends of 
accessibility to food by pastoralist households, and the influence that livelihood exert on pastoralists food security in Narok county. Following this, observational studies and interviews were conducted in three sub-counties namely: Narok North, Narok East and Narok South. Narok County has two main ecological zones: the highlands in which rain fed agriculture is practiced and the fragile lowlands which are mostly used for pastoralism. It is the lowland area that was identified as optimal for data collection, hence they were selected for inclusion in the study. The national road B3 that cuts across the country almost marks the divide between the two zones.

\section{Methodology}

The research designs adopted in the study were the evaluation and descriptive cross-cultural surveys. A part of the methodological research used the Probit model and variability of data through Chi square and pearsons correlation for inferential significance and causal relationships among the coping strategies of the pastoral community's livelihoods assets contribution on household food security in Narok county Kenya from quantitative data collected from residents and key stakeholders..

\section{Results}

Coping strategies of the pastoral community's livelihoods assets contribution on household food security in Narok county kenya

Using the Hunger Module, the study established the general status of food availability in Narok County. The results as displayed in the table 4.1, regarding question E03, when asked if they ate a limited variety of foods due to a lack of choices in the market, 75 per cent of the respondents said yes. When asked if they ate fewer meals in a day because there was not enough food, (E06), 78\% (300) of household heads responded in the affirmative, and when asked whether any household member had gone to sleep at night hungry because there was not enough food (E08), 61\% (235) of the pastoralists answered in the affirmative.

Table 14.1: Table Displaying Responses Regarding Food Availability in Narok County

\begin{tabular}{|l|l|l|}
\hline Hunger Indicator & YES & NO \\
\hline $\begin{array}{l}\text { E03. Did you or any household member eat a limited variety of foods } \\
\text { due to lack of choices in the market? }\end{array}$ & $\begin{array}{l}75 \% \\
(288)\end{array}$ & $25 \%(96)$ \\
\hline $\begin{array}{l}\text { E06. Did you or any other household member eat fewer meals in a day } \\
\text { because there was not enough Food? }\end{array}$ & $\begin{array}{l}78 \% \\
(300)\end{array}$ & $22 \%(84)$ \\
\hline $\begin{array}{l}\text { E08. Did you or any household member go to sleep at night hungry } \\
\text { because there was not enough food? }\end{array}$ & $\begin{array}{l}61 \% \\
(235)\end{array}$ & $\begin{array}{l}39 \% \\
(149)\end{array}$ \\
\hline Mean Average & $71.3 \%$ & $\begin{array}{l}28.6 \% \\
(109)\end{array}$ \\
\hline
\end{tabular}

Source: Researcher, (2017)

Qualitative data from key informants furthered revealed trading activities in food stuffs remains low in his part of Narok county. The lack of dietary diversity is an indication of food insecurity in the domain of availability. 
One key informant asserted,

\section{".. Most of us pastoralists depend mainly on milk and meat from the animals. It is not often we can get fruits and different kinds" Key Informant; Narok, 2017}

Literature (AWS, 2015) indicates that eating fewer meals implies missing some meals owing to inadequacy of food to cater for all meals. In the opinion of the author, pastoralists by the nature of their lifestyle eat less frequent meals than sedentary populations, and therefore, if meals are cut back it indicates a rather severe degree of food unavailability. Again, this follows from the dwindling flocks upon which the pastoral communities depend for food; a coping strategy of cutting back is employed in order to try and preserve the existing stock of herd.

Households were further asked to indicate how food is access affected during a normal year which has at least one drought season. They itemised the key issues that affect their access to food.

Table 4.2: Summary of responses on How access to food is affected during normal year in Narok county Kenya

\begin{tabular}{|l|l|l|}
\hline Ways it is affected & Frequency & Percent \\
\hline During drought the price of food stuffs goes up & 105 & 23.1 \\
\hline Inadequate funds to access food & 72 & 15.8 \\
\hline Low food supply during dry season & 68 & 15.0 \\
\hline Destruction of plants by wild animals & 35 & 7.7 \\
\hline Low food produced & 35 & 7.7 \\
\hline Low prices of livestock affect negatively accessibility of food & 35 & 7.7 \\
\hline Far markets & 34 & 7.5 \\
\hline Total & $\mathbf{3 8 4}$ & $\mathbf{1 0 0}$ \\
\hline
\end{tabular}

Source: Researcher, (2017)

Food availability is affected by distance to markets, destruction of plants by wild animals, low food production, low prices of livestock affect negatively accessibility of food, inadequate funds to access food, low food supply during dry season, fluctuation of prices, and during drought the price of food stuffs goes up.

Production contributes a large part to food availability. Households were asked to indicate the acreage for the crops they grow. This is summarized in table 4.

Table 4.3: Acreage under food Cultivation Narok county Kenya

Source: Researcher, 2017

\begin{tabular}{|l|l|l|}
\hline Acreage & Frequency & Percent \\
\hline None & 282 & 73.4 \\
\hline Less than 1 & 71 & 18.5 \\
\hline $1-4$ & 31 & 8.1 \\
More than 4 & 0 & \\
\hline Total & $\mathbf{3 8 4}$ & $\mathbf{1 0 0 . 0}$ \\
\hline
\end{tabular}


A Chi Square test conducted on the data showed that there was a highly significant $(\mathrm{p}<0.01)$ variation in the crop acreage grown by households ( The results showed that $18.5 \%$ had less than an acre, $8.1 \%$ had $1-4$ acres while a large majority of $73.4 \%$ had not planted food.

Qualitative data through focus group discussions revealed that the that majority of households owned small pieces of land, mainly due to fragmentation as the population grows. Majority of households do not grow crops in the first season and therefore indicated that they devoted no acreage to crops. The study went on to establish that majority acquire their food through purchases rather than own production. This data is presented in Figure 4.1.

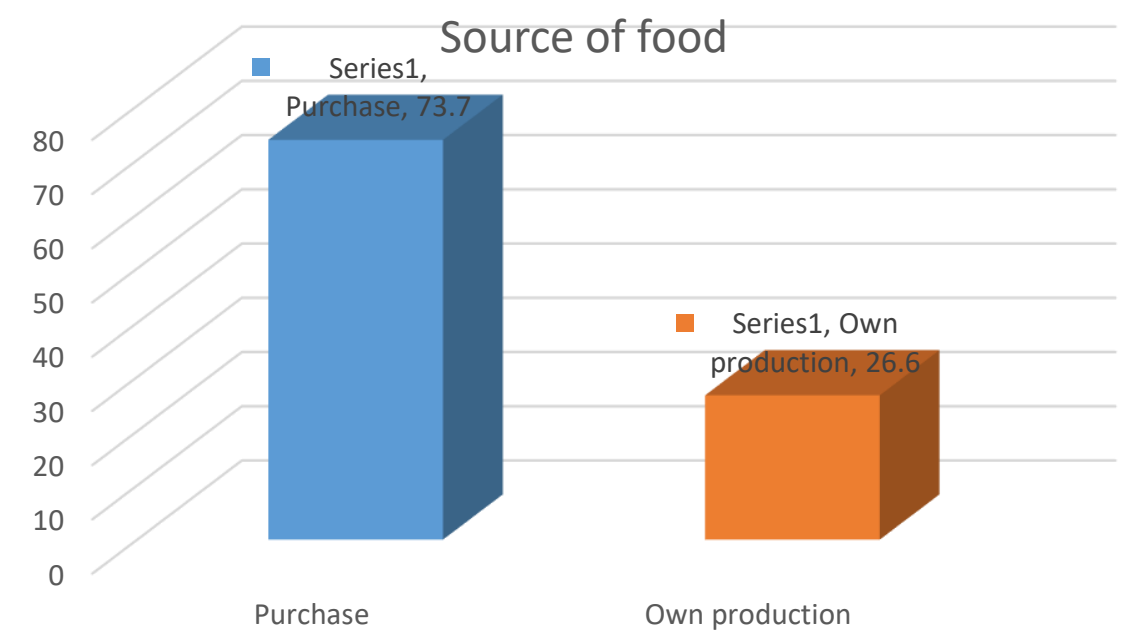

Figure 4.1: Sources of Food for pastoralists of Narok County, Kenya Source: Researcher (2017)

A Chi Square test $\left(\chi_{1,0.01}^{2}=160.42\right)$ showed that there was a highly significant $(\mathrm{p}<0.01)$ difference between households that produced their own food and those that purchased food. From the results shown, $282(73.4 \%)$ of the respondents purchased food while 102(26.6\%) produced their own food. The results show that majority of respondents relied on purchased food. The results are in consistent with those of (Ellis, 1999) who established that of the SSA pastoralists, about 3050 percent of rural households earn income from non-farm livelihoods

One key informant asserted,

“. Most of us pastoralists do not engage in significant forms of agricultural production of food crop due to human animal conflict arising from free roaming wild life animals that share the land and eat crops grown and migratory patterns influenced by rains and weather" Key Informant; Narok, 2017.

The study found that pastoralists occupy the lower Narok county semi-arid area that is also a wildlife dispersal zone it was noted from the FGD key informants that the free movement of wildlife that use the same land as migratory and pasturelands for grazing, it was revealed that in areas where food crops agriculture has been attempted, the results have been of crop failure and losses due invasion of the farmed area by wildlife which has continued to exert huge losses to the 
pastoralists and attempts to get adequate compensation have elicited little response from the wildlife authorities. Land use patterns in Narok have continued to contributes to human -wildlife conflict leading to unavailability and stability in food accessibility utilization and inadequate nutrition status (Hoare, 1999a; Naughton et al., 1999; Hill et al., 2002; Sitatiet al., 2005).

\section{Food accessibility and Consumption of Less Variety and Quality of Food}

Using the hunger module, the study sought to establish status of accessibility to food by the pastoral community in the study area. Accessibility was measured by questions, as summarised in Table 5.1. which is an extract from the Hunger Module.

Table 5.1: Extract of Hunger Module's 8 Questions Food Security

\begin{tabular}{|l|l|}
\hline $\begin{array}{l}\text { FOOD SECURITY } \\
\text { DIMENSIONS }\end{array}$ & KEY QUESTIONS \\
\hline Accessibility & $\begin{array}{l}\text { E4: Did you or any household member eat food that you preferred not to } \\
\text { eat because of a lack of resources to obtain other types of food? } \\
\text { E5: Did you or any other household member eat smaller meals in a day } \\
\text { because of lack of resources to obtain enough? }\end{array}$ \\
& $\begin{array}{l}\text { E7: Was there a time when there was no food at all in your household } \\
\text { because there were not enough resources to go around? }\end{array}$ \\
\hline
\end{tabular}

Source: FAO, 1996. (AWSC, 2015)

\section{Consumption of Less Variety and Quality Of Food}

Households were asked to indicate whether they consumed less quality and variety of food. The results are displayed in Figure 5.1.

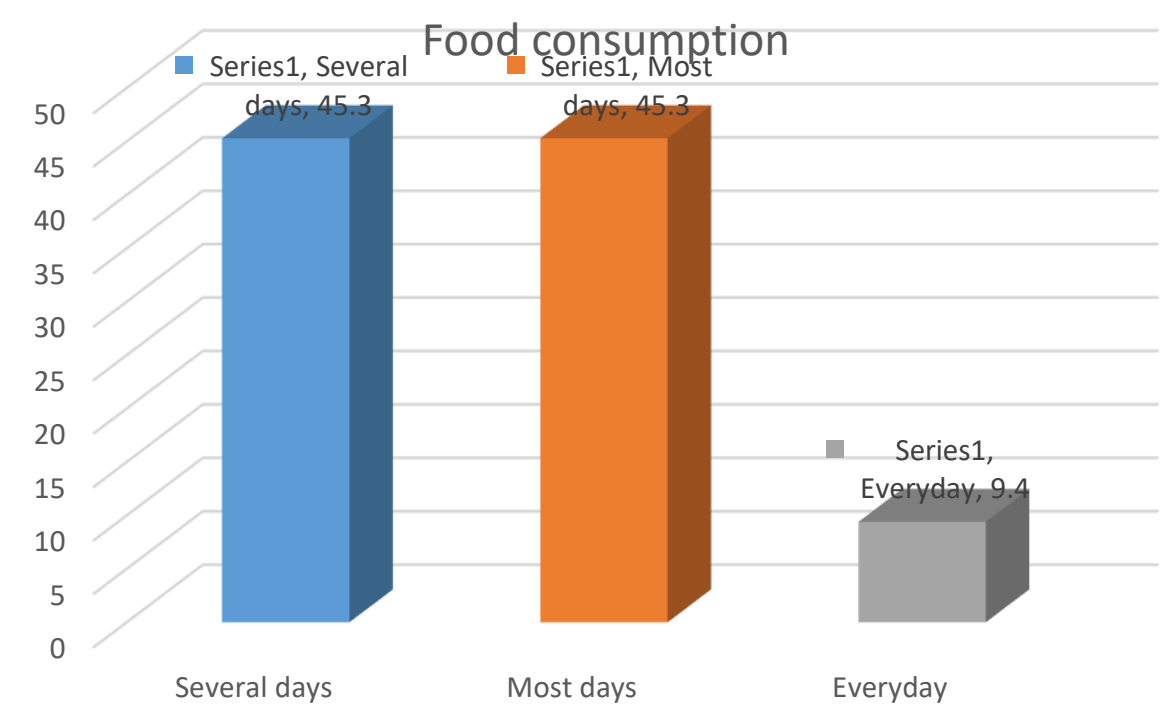

Figure 1 5.1: Household Consuming less Quality \& Variety of food Narok county kenya Source: Researcher (2017) 
A Chi Square test conducted on the data showed that there was a highly significant $(\mathrm{p}<0.01)$ variation in responses on consumption of less quality and variety food $\left(\chi_{2,0.01}^{2}=99.1875\right)$. From the results, 174 (45.3\%) did it several days, 174 (45.3\%) did it most days while 36 (9.4\%) every day. Majority did not experience this on a day to day basis.

"As Pastoralists we have a nomadic life that takes us to places where the livestock (cows) are able to get pasture and water, during the dry season we eat less as the cows produce less milk and we can only draw limited blood to mix with the milk" FGD Informant, Narok 2017. No Food Due to Lack of Resources

The study found that pastoralist households in Narok county limit the portion of meals for all household members.

It was revealed that, up to $94.6 \%(45.6+49)$ of households experience no food for a meal due to lack of resources almost every day. A Chi Square test conducted on the data showed that there was a highly significant $(\mathrm{p}<0.01)$ variation in responses on there being no food at all in the house due to a lack of resources $\left(\chi_{3,0.01}^{2}=305.6345\right)$. From the results, $13(3.4 \%)$ households reported never, $8(2.1 \%)$ experienced this often and, 175 (45.36) said on most days while $188(49.0 \%)$ said it happened every day.

The mean average of the food hunger indices for this domain representing poor access to food is therefore $(94.6+68+54.7) / 3=72.4 \%$.

"Our Pastoralists is migratory and seasonaly takes us far from settled areas where we can buy foodstuffs from traders of maze flour and other foods as alternatives and addative to our normal diet of milk, cows blood and meat during the dry season our herds get depleted by the harsh weather conditions and we cannot slaughter any cow" FGD Informant, Narok 2017

\section{Human Capital and Food Accessibility}

Age

The study sought to establish if and how age affects accessibility of the households to food. Focus group discussants informed the study that older persons have a difficult time walking to the trading centres where food is sold, and even standing in line for long to receive food aid. A Key Informant further confirmed this when he asserted;

"the elderly in this community have a hard time accessing food because of they are not strong enough to walk long distances or work on getting food" Key Informant, Narok 2017

\section{Gender}

Qualitative data also revealed that gender factors affect access to food, mainly for economic and social reasons. It was revealed by a key informant that

'women are financially vulnerable and therefore less able to access food items by purchase. Sometimes women are prohibited to consume certain foods by virtue of their being female' FGD 
Informant, Narok 2017.

\section{Morbidity and Accessibility}

The study learned through focus group discussions that

'a number of households had members who suffer from stomach ulcers or acidity, which prevents them from consuming commonly available foods such as maize and beans. Hence, even when the food is available, such members are unable to consume it FGD Informant, Narok 2017.

\section{Social Capital and Food Accessibility Culture, tradition and Religious Affiliation}

The study, through qualitative data learned that culture plays a role in access to food, because there are certain foods that are culturally unacceptable, and others are culturally recommended

The study was informed through focus group discussants that,

'fish which is considered part of the fish family and chicken which are considered birds which are part of the larger wild animals, birds and reptiles are not to be eaten and therefore taboos' FGD Informant, Narok 2017.

It was also narrated by a key informant that the order in which meals are served with men given preference then children and women, always leave the women and children vulnerable as the servings remaining for women and children to share would almost always be reduced rations key informant (2017).

\section{Informal Institutions (Extended family, relatives, groups)}

Relatives and extended family were found to enhance access to food for the households. The study learned through focus group discussions that, in cases where a household head cannot get food, due to distance, illness or other reason, relatives will bring the food to the household thereby easing access. It was also revealed that it was normal for children or part of the household members to move into the household of a relative who is well off, either within the village or different locations for the periods of food scarcity or stress key informant (2017).

\section{Economic Capital and Food Accessibility}

Economic capital elements play a key part in a household's ability (or lack thereof) to access food. Asked why the supply of food was not enough for their households, their response were summarized in Table 5.2.

Table 5.2: Reasons for Not Having Enough Supply Narok county kenya

\begin{tabular}{|l|l|l|}
\hline Reason & Frequency & Percent \\
\hline Lack of money & 70 & 18.3 \\
\hline Low production & 69 & 18.0 \\
\hline Most people buying on credit & 69 & 18.0 \\
\hline Buying on credit & 69 & 18.0 \\
\hline Few suppliers and many consumers & 36 & 9.4 \\
\hline
\end{tabular}


Source: Researcher (2017)

\begin{tabular}{|l|l|l|}
\hline Poor roads & 36 & 9.4 \\
\hline Unfavourable market prices & 35 & 9.1 \\
\hline Total & $\mathbf{3 8 4}$ & $\mathbf{1 0 0}$ \\
\hline
\end{tabular}

As seen in the table, most of the responses revolved around economic (lack of money, purchase on credit, unfavourable prices) and physical access (poor roads) issues.

A Chi Square test conducted on the data showed that there was a significant $(\mathrm{p}<0.05)$ variation in responses on reasons for not having enough supply $\left(\chi_{6,0,05}^{2}=33.9054\right)$. The reasons cited included lack of money, low production, most people buying on credit, few suppliers and many consumers, poor roads, and unfavourable market prices.

\section{Coping for Stability in Food Accessibility}

To measure stability in food accessibility, pastoralist household heads were asked whether they had physical, economic and social access to food at all times. The responses are as recorded in Figure 5.6

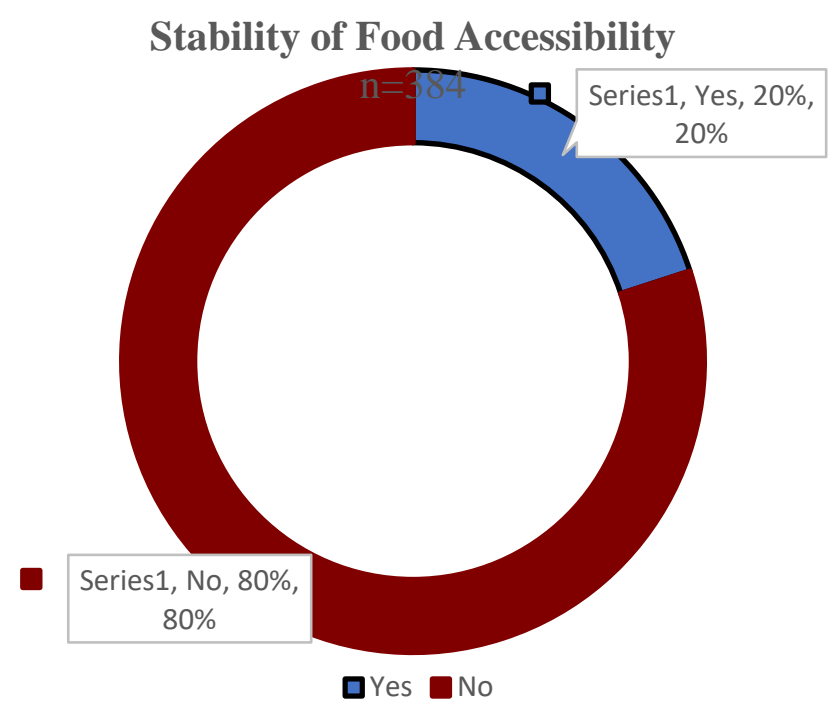

Figure 2 5.6 Stability of Food Accessibility Narok county Kenya

Source: Researcher (2017)

From the findings, $80 \%$ (307) pastoralist households in Narok county admitted that they are not always able to have physical, economic and social access to the food their households need. Only $20 \%$ () claimed to always have access. Qualitative data revealed some of the reasons for the status quo. A key informant stated the following;

"Pastoralist households suffer difficulties in accessing food mostly because of recurrent drought, livestock diseases, wild animal destruction, poor farming methods, and a general lack of capital” Key Informant, Narok, 2017 


\section{Conclusions}

Based on the specific objectives, the following conclusions were drawn

1) The human, social and economic capital of the pastoralist influences the household food availability by affecting the ability to produce or trade in food. The livelihoods also influence the food availability through the giving of food aid. The stronger the livelihoods, the more secure the food availability.

2) Household Food Accessibility for pastoral households in Narok County of Kenya is influenced by their livelihoods. The human, social and economic capital directly influence the physical, social and economic access to food by the households.

3) The livelihood (human, social and economic) of the pastoral community influences their food utilizations by determining the household's access to potable water, ownership of a latrine and safe food storage practices.

\section{Recommendations}

The county government should engage local leaders to encourage the community to diversify their livelihoods beyond livestock keeping and trading in the products thereof. Diversification of sources of income can assist in enhancing food availability.

Nomadic pastoralism as practiced within the study area is further shrinking. Diversification becomes a necessity. In order to sustain the endangered livelihood. Farming of non-traditional animals like pigs and rabbits need to be explored, as well as bee keeping and herd value addition to the existing herds- improvement of quality of animals through proper animal husbandry, as well exploration of dry land farming can also be explored.

Most of the pastoralists areas are amongst the last frontier in wildlife dispersion, proper land use that includes ecotourism can be both beneficial for the survival of species and livelihood support for ASAL areas.

Road networks within the county should be improved to ease access to trading centres and markets thereby easing access to food.

public education efforts should be enhanced to encourage more latrine coverage in pastoral households.

\section{References}

[1] African Women's Studies Centre AWSC (2015) Food Security Research Findings and Recommendations. Makueni County

[2] Alonso B. E. (2015) The impact of culture, religion and traditional knowledge on food and nutrition security in developing countries. FOODSECURE Working paper no. 30 March 2015

[3] Anglia, UK. (2014). January. http://www.fao.org/es/esw/lsp/cd/img/docs/lspwp9.pdf (Accessed 6 January 2014).

[4] Barbier, B and Hochard, J. (2014). Poverty and the spatial distribution of rural population (SSRN) Scholarly Paper No. ID 2522735). Social Science Research Network, Rochester, New York. 
[5] BehnkeRH(2008)The economic contribution of pastoralism: case studies from the horn of Africa and Southern Africa. Nomadic Peoples 2008,12(1):45-79. 10.3167/np.2008.120104

[6] Blench, R. (2004). Natural resource conflicts in North-Central Nigeria: A handbook and case studies. Cambridge: MallamDendo Ltd.

[7] Bigsten, A. (1984). Regional Inequality and Development: A Case Study of Kenya. Gower Publishing, Farnham.

[8] Colding, Johan, and Carl Folke. (1997). The Relations among Threatened Species, Their Protection, and Taboos. Conservation Ecology. 2001. "Social Taboos: 'Invisible' Systems of Local Resource Management and Biological Conservation." Ecological Applications 11: 584-600

[9] CGIAR. (2016). Strategies for Combating Climate Change in Dry Lands Agriculture. Palmira, Valle del Cauca, Colombia: Climate Change, Agriculture and Food Security.

[10] Davies, S. and N. Hossain. (1997). Livelihood adaptation, public action and civil society: a review of the literature. IDS working paper, 57. Brighton: IDS.

[11] DFID (2009). Managing dryland pastoral systems: implications for mitigation and adaptation to climate change.

[12] DFID. (2000). Sustainable Livelihoods Guidance Sheets. Department for International Development. Retrieved from http://www.livelihoods.org/info/info_guidancesheets.html accessed: 12.10.2016.

[13] Dolan C.J. 2004. Access All Areas: Improving Access to Schooling by Distance Education in Australia, paper presented at the All-Africa Ministers' Conference on Open Learning and Distance Education Cape Town International Convention Centre, Monday, 2 February 2004, http://www.africaodl.org/conference/odl.htm.

[14] Ellis, F. \& Allison, E. (2004). Livelihood Diversification and Natural Resource

[15] Access. Food and Agriculture Organisation of the United Nations, Livelihood Support Programme Working Paper 9, Overseas Development Quintile, University of East

[16] Ellis, F. (2000). Rural livelihoods and diversity in developing countries. Oxford: Oxford University Press

[17] Ellis, F. (1999). Rural livelihood diversity in developing countries: evidence and Policy implications. Natural Resources Perspective, No. 40, April 1999. Overseas Development Institute 130

[18] Food and Agriculture Organization of the United Nations (FAO). (2016.). Pastoral Systems Worldwide. Rome: FAO. Retrieved 28 April 2016, from http://www.fao.org/docrep/005/y2647e/y2647e02.htm

[19] FAO, WFP and IFAD. (2012). The State of Food Insecurity in the World 2012. Economic growth is necessary but not sufficient to accelerate reduction of hunger and malnutrition. Rome, Food and Agriculture Organization.

[20] FAO: Livestock (2012) sector brief. Kenya; 2005.http://www.fao.org/ag/againfo/ resources/en/publications/sector briefs/lsb_KEN.pdf. Accessed 22 February 2012Google Scholar.

[21] FAO, (2007). Livelihoods Assessment and Analysis Lesson 1 Introduction to Livelihoods Learner Notes

[22] FAO: (1996). Rome Declaration on World Food Security and World Food Summit Plan of Action. World Food Summit 13-17 November 1996. Rome

[23] Fitzgibbon, C. (2012). Economics of Resiliense Study: Kenya Country Report. Online. https://www.gov.uk/government/uploads/system/uploads/attachment_data/file/228500/TEERR_K enya_Background_Report.pdf (Accessed May 1, 2014).

[24] Galaty, J. G.; Article:(1993) "Maasai Expansion and the New East African Pastoralism" in Spear, T. and Waller, R. eds.; Being Maasai: Ethnicity and Identity in East Africa; James Currey Ltd.; London, 1993

[25] GEF (Global Environment Fund), (2007) UNDP (United Nations Development Programme) And IUCN (International Union for Conservation of Nature) 2007. Squandered Wealth: A Global Economic Review of Pastoralism, WISP Policy Issues Paper 2. IUCN, Nairobi. 
[26] GoK.( 2010):National climate change response strategy. Government Press, Nairobi;

[27] Gittelsohn, J., Meera T., and Landman. L. T. (1997) Cultural Factors, Caloric Intake and Micronutrient Sufficiency in Rural Nepali Households. Social Science \& Medicine 44 (11): 173949. doi:10.1016/S0277-9536(96)00375-9.

[28] Green, D. (2012). From poverty to power: How active citizens and effective states Can change the world, 2nd ed. Rugby, UK: Practical Action Publishing and Oxford: Oxfam International.

[29] Henrich, J. and Henrich. N. (2010). The Evolution of Cultural Adaptations: Fijian Food Taboos Protect against Dangerous Marine Toxins. Proceedings of the Royal Society B: Biological Sciences 277 (1701): 3715-24.

[30] Hill, C., Osborn, F. \&Plumptre, A.J. (2002). Human-wildlife conflict: identifying the problems and possible solutions. Albertine rift technical report series Vol. 1. New York: Wildlife Conservation Society.

[31] Hoare, R.E of human-elephant conflict in a land use mosaic. J. Appl. Ecol. 36, 689-700.

[32] Institute for Environment and Development iied, (2009) Mobile Pastoralists and Education: Strategic Options

[33] Jansen, J. 2005. Targeting education: The politics of performance and the prospects of 'Education For All'. International Journal of Educational Development 25(4) pp. 368-380.

[34] Khatun, D. \& Roy, B.C. (2012). Rural livelihood diversification in West Bengal:determinants and constraints, Agricultural Economics Research Review, 25(1): 115-124. http://ageconsearch.umn.edu/bitstream/126049/2/12-Dilrub.pdf (Accessed 7 January 2014).

[35] Kaimba G, Njehia B, GuliyeA. (2011).Effects of cattle rustling and household characteristics on migration decisions and herd size amongst pastoralists in Baringo District, Kenya.Pastoralism: Research, Policy and Practice 2011,1(1):1-18. 10.1186/2041-7136-1-1

[36] Kiringai, J. (2006). Public spending in Kenya: An inequality perspective. In (SID (Society for International Development), ed.) Readings on Inequality in Kenya: Sectoral Dynamics and Perspectives, pp. 11-56. SID, Nairobi.

[37] KNBS:(2009) Kenya population and housing census. KNBS, Nairobi; 2010.Google Scholar kKristjanson, P.; Radeny, M.; Nkedianye, D.; Kruska, R.; Reid, R.; Gichohi, H.; Atieno, F. and Sanford, R.(2002) Valuing Alternative Land-use Options in the Kitengela Wildlife Dispersal area of Kenya; ILRI Impact Assessment Series 10; A Joint ILRI (International Livestock Research Institute)/ACC (African Conservation Centre) Report; ILRI; Nairobi, Kenya; 2002.

[38] Kothari C. (2011), Research Methodology; Methods and Techniques. Delhi, India.

[39] Liu, Yan Qun, Petrini M., and. Maloni J. A. (2014). Doing the Month: Postpartum

[40] Practices in Chinese Women. Nursing \& Health Sciences, June, n/a - n/a. doi:10.1111/nhs.12146.

[41] Matsumoto D., and Juang L. (2012). Culture and Psychology. Cencage Learning

[42] Markakis, J. (2004). Pastoralism on the Margin. London: Minority Rights Group International.

[43] Mugenda A.G., Mugenda M.O. (2003). Research Methods Quantitative and qualitative approaches. Nairobi: Acts Press.

[44] Mtika.M.M (2001) The AIDS Epidemic in Malawi and its Threat to Household Food Security Human Organization Summer 2001, Vol. 60, No. 2, pp. 178-188 accessed at https://doi.org/10.17730/humo.60.2.cnlpmfrrg8hay9xh

[45] Mung'ong'o, C.; and Mwamfupe, D.; (2011). Poverty and Changing Livelihoods of Migrant Maasai Pastoralists in Morogoro and Kilosa Districts, Tanzania; Research Report No. 03.5; MkukinaNyota Publishers Ltd; Dar es Salaam, 2003 http://www.repoa.or.tz (27/11/2012)

[46] Nachmias, Frankfort- C. and Nachmias, D. (2002), Research Methods in Social Sciences. New York: St. Martin's Press

[47] Napoli, M., De Muro, P., Mazziotta, M. (2011) Master In Human Development And

[48] Food Security (2010/2011) Towards a Food Insecurity Multidimensional Index (FIMI)

[49] Naughton-Treves, L. (1998). Farming the forest edge: vulnerable places and people around Kibale National Park,Uganda. Geogr. Rev. 87, 27-47. Naughton-Treves, L., Rose, R. \& Treves, A. (1999). 
Social dimensions of HEC in Africa: a literature review and case studies from Uganda and Cameroon. Gland, Switzerland:Human Elephant Conflict Taskforce, IUCN.

[50] Nyanjom O, (2014). Remarginalising Kenyan Pastoralists: The Hidden Curse Of National Growth And Development, Kenya Institute for Public Policy Research and Analysis.

[51] Opiyo, F.E.O.et al. (2014). Measuring household vulnerability to climate-induced stresses in pastoral rangelands of Kenya: Implications for resilience programming. Pastoralism: Research, Policy and Practice,4(10),1-15. https://doi.org/10.1186/s13570-014-0010-9

[52] Opiyo FEO, Mureithi SM, Ngugi RK (2011). The influence of water availability on pastoralist's resource use in Kitui and Mwingi districts of Kenya. Journal of Human Ecology 2011,35(1):4352.

[53] Sabaté, J. (2004.) Religion, Diet and Research. British Journal of Nutrition 92 (02): 199-201.

[54] Scoones, I. (1998). Sustainable rural livelihoods: a framework for analysis. IDS working paper, 72. Brighton: IDS.

[55] Samwel K. N. (2014) Socio-Economic Factors Affecting Food Security In Households Of Elderly Persons In Imenti Central Sub County, Meru County, Kenya

[56] Smith, E. (2008). Using secondary data in educational and social research. New York: Open University Press.

[57] Sitati N.W., Walpole M.J. and Leader-Williams N. (2003) Mitigating human elephant conflict outside protected areas in Africa: Crop raiding in Transmara district Kenya. J. Appl. Ecol. 42 11751182

[58] Start, D. (2001). Rural diversification: what hope for the poor? Overseas Development Institute. http://www.odi.org.uk/publications/4818-rural-diversification-hope-poor(Accessed 10 January 2014).

[59] Swift, J. \& Hamilton, K. (2001). Household Food and Livelihood Security. In: S. Devereux and S. Maxwell (Eds.), Food Security in Sub-Saharan Africa (pp. 67-92). London. ITDG Publishing.

[60] Tapsell, L. C., Hemphill I., Cobiac, D., Sullivan R., Fenech M., Patch C, and Roodenrys,.(2006). Health Benefits of Herbs and Spices: The Past, the Present, the Future. Medical Journal of Australia 185 (4): $S 1-24$.

[61] Tarus, I. K. (2005). A History of the Direct Taxation of the African People of Kenya, 1895-1973. $\mathrm{PhD}$ thesis, Rhodes University, South Africa.

[62] Tobin, J. C. (2009). Hunger Efforts and Food Security. New York: Nova Science Publishers, Inc.

[63] United Nations Development Programme; Sustainable Livelihoods.(2015) Concepts, Principles and Approaches to Indicator Development;

http://www.undp.org/SL/documents/indicatorsand_eval (26/10/11)

[64] UNISDR (2014) Living with risk: a global review of disaster reduction initiatives

[65] United Nations. (1975). Report of the World Food Conference, Rome 5-16 November 1974. New York.

[66] Uusiku, N. P., André Oelofse A., Duodu K., Bester J. M., and Faber M. (2010)

[67] Nutritional Value of Leafy Vegetables of Sub-Saharan Africa and Their Potential Contribution to Human Health: A Review. Journal of Food Composition and Analysis 23(6): 499-509.

[68] Valentine, G. (1997). Tell Me About Using Interviews as a Research Methodology. In: Flowerdew, E. and Martin, D. (eds.). Methods in Human Geography; a Guide for Students Doing a Research Project, pp 110-253. Longman, London.

[69] Yanda and William in Kwiyikamba. (2005). The Changing Livelihoods in the Maasai Plains; The Guardian, IPP Media Ltd at http://www.skyfm.co.tz/ipp/guardian/2005/05/02/40498.htm

[70] Yurco Kayla Marie, (2011). PASTORAL MOVEMENTS AND MOVEMENTS IN PASTORALISM: SHIFTING TRADITIONS AND INSTITUTIONS OF MODERN MANAGEMENT STRATEGIES IN LAIKIPIA, KENYA

[71] Zaal, F. and Dietz, T.; Article:(1999) “Of Markets, Meat, Maize \& Milk: Pastoral 
[72] Commoditization in Kenya" in Anderson, D. M. and Broch-Due, V.; The Poor Are Not Us: Poverty and Pastoralism in Eastern Africa; James Currey Ltd; Oxford; Ohio University Press; Ohio, and East African Educational Publishers; Nairobi, 1999.

*Corresponding author.

E-mail address: tmantai@ newinternational.org 